systems ${ }^{10}$ will have a key role in ensuring it doesn't result in less efficient working practices-for example, longer lengths of stay.

The impact on existing NHS facilities also needs to be considered. Some NHS providers may have a higher proportion of emergency cases than other providers. This will need to be better managed, with an increased ability to predict likely variations in demand and match resources to manage it more effectively. NHS providers are also more likely to deal with the more complex cases, which has implications for resource requirements. And they may be required to manage complications arising from non-NHS providers-clear processes and protocols will need to be in place to underpin this.

Integrating new providers with existing NHS organisations more generally will be important. The interface between primary care and intermediate care, for example, will need to be carefully managed to ensure that improved care pathways can be realised.

Finally, the implications for staffing will be important. Initially, the new providers will be largely staffed by overseas clinicians. Over time, however, UK trained staff may apply for posts in these organisations. The NHS will have to become a "better employer" to compete for staff as well as for patients.

\section{Where next?}

If this limited outsourcing of elective care to the private sector proves successful, where might the government look to next? Diagnostics could be the next area of focus. Both major political parties have already aired the concept of vouchers, and diagnostics would be ideal for a pilot. Potentially any patient needing one of a shopping list of diagnostic procedures or an annual health check could be given a voucher to redeem where they chose. This could be with existing providers of diagnostic services, such as Alliance Medical, or new providers, such as supermarkets, gyms, or high street pharmacists. ${ }^{11}$

Primary care could also be opened up to new players. Some entrepreneurs are already spotting an opportunity and developing new private primary care services. Examples include Primecare, U-FirstHealthcare, and Doctors Direct.

But perhaps most interest will come from new approaches in the management of chronic disease. ${ }^{12}$ Encouraged by research suggesting that better integrated care can reduce costs,${ }^{13}$ the government has funded two US companies (Kaiser Permanente and United Healthcare) to work with primary care trusts across England to explore the potential to deliver care in new ways. The next step could be for primary care trusts to contract directly with organisations to provide care for groups of patients with chronic diseases such as asthma, diabetes, or heart disease.

\section{Conclusions}

The government's recent attempts to open up the UK healthcare market to new providers look set to continue. This could result in a dramatically different healthcare system-one in which the NHS is a commissioner or purchaser of healthcare services provided by a range of organisations, all competing to drive up quality and efficiency to ensure they attract more patients. Will it work?

\section{Summary points}

Several new private providers have recently been awarded contracts to provide healthcare services for the NHS

In future, NHS organisations will compete with private providers to attract patients

New providers are introducing new ways of working, resulting in faster throughput and lower costs than traditional private providers

Existing providers (NHS and private) are having to re-examine how they provide care

The initiative may expand to include diagnostics, primary care, and chronic disease management services

Only time will tell. But if the airline business is anything to go by, things will certainly be different, and the cosy duopoly of the NHS and mainstream private providers will be a thing of the past.

Competing interests: PD works as a paid advisor to a range of organisations including the NHS, think tanks, charitable organisations, pharmaceutical companies, McKinsey \& Co, and private sector healthcare providers.

Department of Health. Fair to all, personal to you. London: DoH, 2003.

Department of Health. The NHS plan. London: DoH, 2000.

Department of Health. Delivering the NHS plan. London: DoH, 2002

Department of Health. Growing capacity-diagnosis and treatment centres. www.doh.gov.uk/growingcapacity/news.htm (accessed 27 Oct 2003).

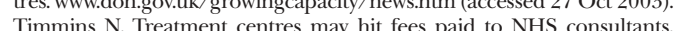
Financial Times 2003 Dec 29

6 Department of Health. Speedier surgery for thousands of patients. Press release 2004/0014, 12 Jan 2004. www.info.doh.gov.uk/doh/intpress.nsf/ page/2004-0014? OpenDocument (accessed 12 Jan 2004).

7 Mango PD, Shapiro LA. Hospitals get serious about operations. McKinse Quarterly 2001;2. www.mckinseyquarterly.com (accessed 27 Jan 2003).

Lewis R, Dixon J. Rethinking management of chronic diseases. $B M$ 2004;328:220-2.

Toynbee P. Market forces are going to kill off private healthcare. Guardian 2003 Oct 22.

10 Department of Health. Reforming NHS financial flows: introducing payment by results. London: $\mathrm{DoH}, 2002$.

by results. London: DoH, 2002.
Dash P. Milk, bread ... smear test. Guardian 2003 Apr 29.

11 Dash P. Milk, bread ... smear test. Guardian 2003 Apr 29. Dixon J, Lewis R, Rosen R, Finlayson B, Gray D. Can the
US managed care organisations? BMJ 2004;328:223-6.

13 Feachem R, Sekri N, White K. Getting more for their dollar: a comparison of the NHS with California's Kaiser Permanente. BMJ 2002;324:135-43. (Accepted 15 January 2004)

\section{Endpiece}

\section{Expelling patients 1778}

Such patients are to be expelled from the infirmary: (1) Who at their admission falsified their disease, or intentionally concealed any material part of it. (2) Who refuse the food, drink, medicines, or operations prescribed, or take any medicines, drink, or food, not ordered by the physicians or surgeons.

The History and Statutes of the Royal Infirmary of Edinburgh. Edinburgh: E Balfour and Smellie, 1778:76-7

Jeremy Hugh Baron, honorary professorial lecturer, Mount Sinai School of Medicine, New York 